\title{
Induction of apoptosis by nitric oxide in macrophages is independent of apoptotic volume decrease
}

\author{
S Hortelano', M Zeini ${ }^{1}$, A Castrillo ${ }^{1}$, AM Alvarez ${ }^{2}$ and \\ L Boscá*,1 \\ 1 Instituto de Bioquímica (Centro Mixto CSIC-UCM), Facultad de Farmacia. \\ Universidad Complutense. 28040 Madrid, Spain \\ 2 Centro de Citometría de Flujo y Microscopía Confocal, Facultad de Farmacia. \\ Universidad Complutense. 28040 Madrid, Spain \\ * Corresponding author: L Boscá, Instituto de Bioquímica, Facultad de Farmacia, \\ 28040 Madrid, Spain. Fax: 34915447254 and 3491394 1782; \\ E-mail: boscal@farm.ucm.es
}

Received 5.11.01; revised 20.12.01; accepted 2.1.02

Edited by J Stamler

\begin{abstract}
Apoptosis occurs through a sequence of specific biochemical and morphological alterations that define the progress of cell death. The changes of the mitochondrial inner membrane potential $\left(\Delta \Psi_{\mathrm{m}}\right)$, the release of cytochrome $c$ to the cytosol, the apoptotic volume decrease (AVD) and the activation of caspases have been measured in RAW 264.7, HeLa and Jurkat T cells incubated with molecules that induce apoptosis through the mitochondrial pathway. Our data show that NO, staurosporine, etoposide and camptothecin increased $\Delta \Psi_{m}$ in macrophages but not in HeLa and Jurkat cells, that exhibited a $\Delta \Psi_{m}$ decrease. Moreover, the apoptosis induced by NO in macrophages, but not that promoted by staurosporine, might occur in the absence of AVD. Analysis of the sequence of apoptotic manifestations shows that $\Delta \Psi_{\mathrm{m}}$ precedes AVD and caspase activation in RAW 264.7 cells. Inhibition of AVD abrogates apoptosis in HeLa and Jurkat T cells regardless of the stimuli used. These data suggest that the changes of $\Delta \Psi_{m}$ are cell-type dependent and that AVD is dispensable for apoptosis in macrophages.

Cell Death and Differentiation (2002) 9, 643-650. DOI: 10.1038/ sj/cdd/4401017
\end{abstract}

Keywords: apoptosis; inflammation; cell volume; macrophages; nitric oxide; cellular activation

Abbreviations: SITS, 4-acetamido-4'-isothiocyanostilbene; AVD, Apoptotic Volume Decrease; CMXRos, chloromethyl X-rosamine; IFN $\gamma$, interferon $\gamma$; LPS, lipopolysaccharide; $\Delta \Psi_{\mathrm{m}}$, mitochondrial inner membrane potential; $m \mathrm{CICCP}$, carbonylcyanide $m$ chlorophenylhydrazone; GSNO, S-nitrosoglutathione; NOS, NO synthase; PG, prostaglandin; $\mathrm{PI}$, propidium iodide

\section{Introduction}

Apoptosis occurs through a series of well defined sequential biochemical changes that conform the apoptotic phenotype. ${ }^{1-3}$ Cell volume loss has been recognized as an early event occurring almost in all apoptotic cells. ${ }^{4-7}$ However, the relevance of this normotonic cell shrinkage in relation to the occurrence of apoptotic death has been a subject of debate. Various groups, working with different cells, reported that cell shrinkage occurs early the apoptotic process, preceding other biochemical and morphologic changes such as release of cytochrome $c$ from the mitochondria, activation of caspases and DNA cleavage, ${ }^{7-9}$ but following rapid signaling events such as the loss of $\Delta \Psi_{\mathrm{m}}$ and the activation of several early protein kinase cascades. ${ }^{10-12}$ Inhibition of apoptotic volume decrease (AVD) impaired apoptosis in various cell types, whereas pharmacological inhibition of caspases in HeLa and U937 cells did not affect AVD. ${ }^{7,8}$ However, broad spectrum inhibitors of caspases (for example, z-VAD.fmk) abrogated AVD and cell death in thymocytes and B lymphocytes. ${ }^{13,14}$

AVD appears to be due to $\mathrm{K}^{+}$release from cells via $\mathrm{K}^{+}$ channels in an electroneutral way implying an efflux of anions and water, the latter responsible for cell shrinkage. ${ }^{7,8}$ In agreement with these suggestions, cell shrinkage caused by hyperosmotic stress or $\mathrm{K}^{+}$ionophores induced apoptosis. 7,15,16 Conversely, inhibitors of $\mathrm{K}^{+}$channels prevented, at least partially, AVD and apoptosis in various cell types. ${ }^{14,17}$

Most of these studies have been accomplished inducing apoptosis with molecules that interfere in mitochondrial function such as staurosporine, etoposide and camptothecin. ${ }^{7}$ Under these conditions, an early apoptotic event is

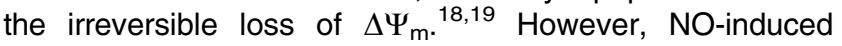
apoptosis in macrophages, a mechanism that contributes to the resolution of inflammation, involves a sustained increase in $\Delta \Psi_{\mathrm{m}}$ compatible with the release of mitochondrial mediators of apoptosis. ${ }^{20,21}$ In view of the precedent data we decided to investigate whether a relationship exists between the changes of $\Delta \Psi_{\mathrm{m}}, A V D$ and apoptosis in three distinct cell types: the macrophage cell line RAW 264.7, Jurkat $\mathrm{T}$ cells and HeLa cells and using NO, staurosporine, etoposide and camptothecin as inducers of apoptosis. Our data show that these molecules promote a rapid increase in $\Delta \Psi_{\mathrm{m}}$ in macrophages, followed by AVD, release of cytochrome $c$, activation of caspases and DNA fragmentation. Inhibition of AVD abrogates apoptosis except in RAW 264.7 cells treated with NO donors. However, in HeLa and Jurkat cells, NO and staurosporine decrease $\Delta \Psi_{\mathrm{m}}$ at the time that apoptosis is significantly impaired by AVD inhibitors. These results indicate that the changes of $\Delta \Psi_{\mathrm{m}}$ leading to apoptosis are cell typedependent and the requirement of AVD for apoptosis progression is dispensable under certain circumstances. 


\section{Results}

\section{Cell type-specific changes of $\Delta \Psi_{\mathrm{m}}$ during apoptosis}

The effect of molecules that promote the release of mitochondrial mediators of apoptosis on the changes of $\Delta \Psi_{\mathrm{m}}$ was analyzed in different cell types. As Figure $1 \mathrm{~A}, \mathrm{~B}$ shows, treatment of RAW 264.7 cells with staurosporine, etoposide, camptothecin and NO-donors, or activation with LPS plus IFN $\gamma$ to express NOS-2, promoted apoptosis through a mechanism that involved an increase in CMXRos fluorescence that can be associated with a rise in $\Delta \Psi_{\mathrm{m}}$. Inhibition of NO synthesis by $1400 \mathrm{~W}^{21}$ in cells stimulated with LPS and IFN $\gamma$ impaired $\Delta \Psi_{m}$ changes and other apoptotic manifestations, indicating that apoptosis is mainly dependent on the synthesis of NO under these conditions of macrophage activation. On analysis, NO and other proapoptotic stimuli, produced an increase in the fluorescence of CMXRos that was reverted upon $\mathrm{mCICCP}$ treatment (Figure 1D). Moreover, when the release of cytochrome $c$ from the mitochondria to the cytosol was measured, all inducers of apoptosis promoted its release, and agreement was observed between the increase in CMXRos fluorescence, the cytosolic levels of cytochrome $c$ and the in vitro activation of caspases 9 and 3 (Figure $1 \mathrm{C}-\mathrm{F}$ ). In addition to macrophages, the same panel of pro-apoptotic stimuli was assayed in Jurkat and HeLa cells. As Figure 2A,B shows, GSNO, staurosporine, etoposide and camptothecin induced apoptosis in Jurkat $T$ cells, and a decrease in $\Delta \Psi_{\mathrm{m}}$ was observed in all these conditions. When the DEVDase activity was measured, the values exhibited a profile that paralleled the decrease of CMXRos fluorescence. As expected, DEVDase activity and apoptosis (not shown) were inhibited by z-VAD (Figure $2 \mathrm{C}$ ). Similar results were obtained in HeLa cells although camptothecin promoted an important DEVDase activation and DNA fragmentation, with a minor decrease in CMXRos fluorescence (Figure 3). These results suggest that, depending on the cell type, an increase (macrophages) or decrease (Jurkat and HeLa) in $\Delta \Psi_{\mathrm{m}}$ occurs during apoptosis, and that the irreversible
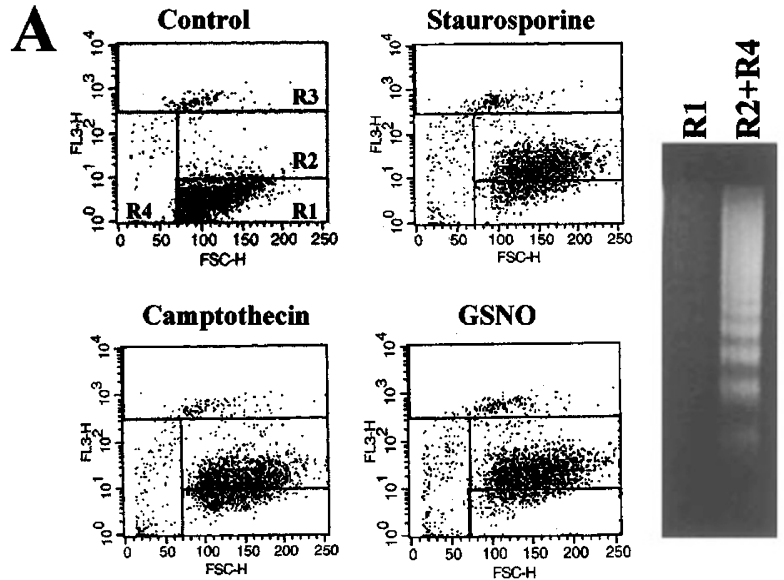

C

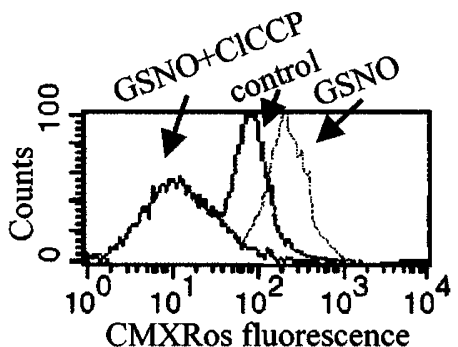

$\mathbf{E}$

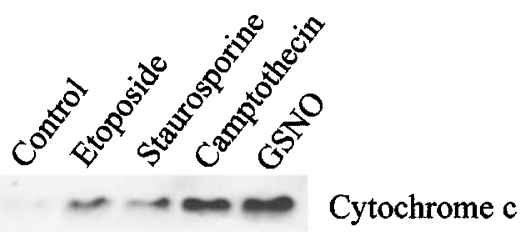

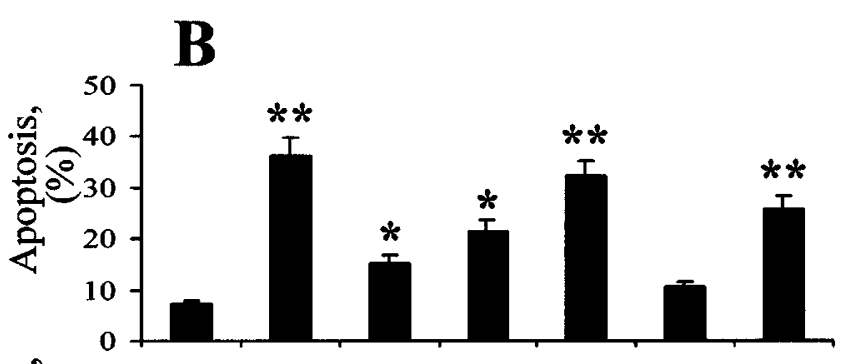
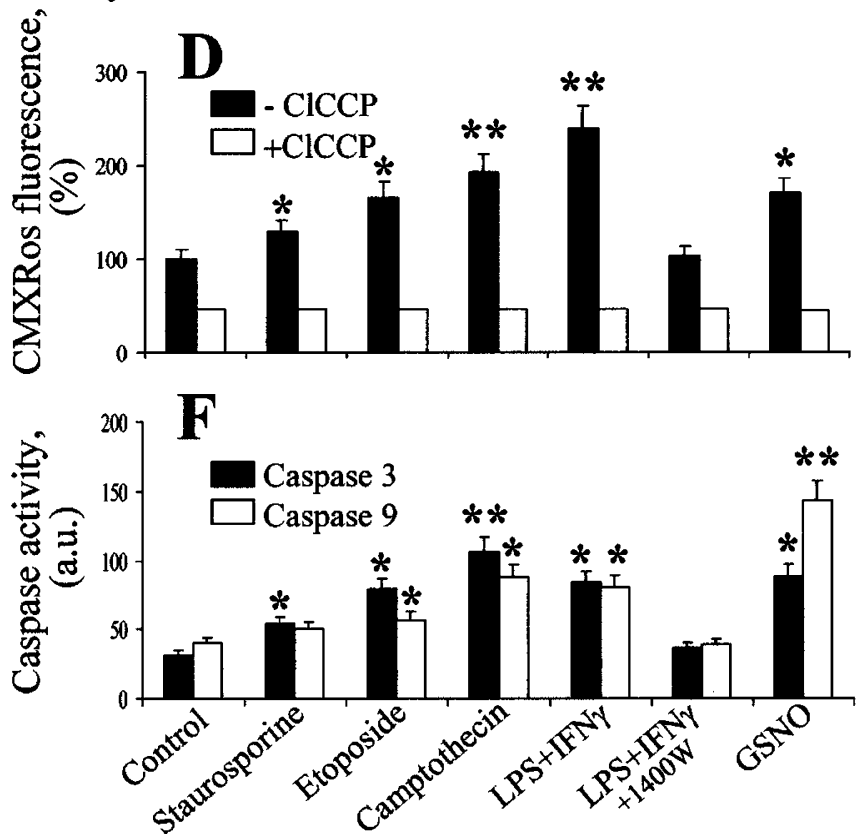

Figure 1 Characterization of apoptosis in RAW 264.7 cells. Macrophages were incubated with $200 \mathrm{nM}$ staurosporine, $1 \mu \mathrm{M}$ etoposide, $1 \mu \mathrm{M}$ camptothecin, $1 \mathrm{mM}$ GSNO, LPS/IFN $\gamma(200 \mathrm{ng} / \mathrm{ml}$ and 20 units/ml, respectively) and $100 \mu \mathrm{M} 1400 \mathrm{~W}$. Apoptosis was determined by flow cytometry followed by cell sorting and DNA fragmentation analysis on agarose gels $(\mathbf{A}, \mathbf{B})$. The changes of $\Delta \Psi_{\mathrm{m}}$ were determined by flow cytometry measuring the fluorescence of cells labeled with $\mathrm{CMXRos}$. Incubation for $10 \mathrm{~min}$ with $10 \mu \mathrm{M} \mathrm{mCICCP}$ was used to depolarize the mitochondrial inner membrane (C,D). The presence of cytochrome $c$ in the cytosol was determined by Western blot $(\mathbf{E})$ and the activity of caspases 9 and 3 was measured by fluorometry $(\mathbf{F})$. Data show the mean \pm S.D. of four experiments. ${ }^{\star} P<0.05$, ${ }^{* *} P<0.01$ with respect to the control condition 
Table I. Changes of parameters involved in early apoptotic signaling in different cell types. Cells were treated as described for Figure 1.

\begin{tabular}{|c|c|c|c|c|c|c|c|c|}
\hline \multirow{2}{*}{$\begin{array}{l}\text { Parameter } \\
\text { Stimulus } \rightarrow \\
\text { Cell type } \downarrow\end{array}$} & \multicolumn{3}{|c|}{ CMXRos fluorescence } & \multicolumn{3}{|c|}{ Release of Cytochrome $c$} & \multicolumn{2}{|c|}{$\begin{array}{l}\text { Requirement of AVD } \\
\text { for caspase activation }\end{array}$} \\
\hline & NO & Stau & Camp & NO & Stau & Camp & NO & Stau \\
\hline Raw 264.7 & $\uparrow$ & $\uparrow$ & $\uparrow$ & yes & yes & yes & no & yes \\
\hline HeLa & $\downarrow$ & $\downarrow$ & $\downarrow$ & yes & yes & yes & yes & yes \\
\hline Jurkat & $\downarrow$ & $\downarrow$ & $\downarrow$ & yes & yes & yes & nd & nd \\
\hline
\end{tabular}

Stau, staurosporine; Camp, camptothecin; nd, not determined.

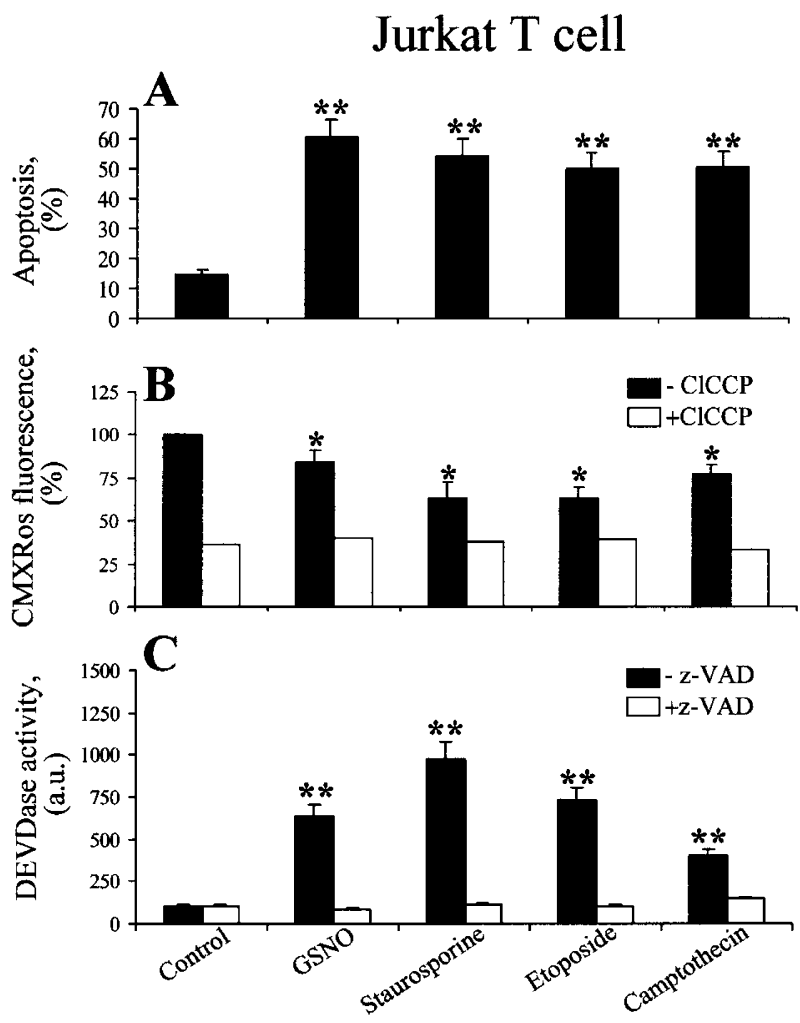

Figure 2 Characterization of apoptosis in Jurkat T cells. Apoptosis was induced with the indicated molecules used at the concentrations employed in Figure 1. The percentage of apoptotic cells was determined by flow cytometry (A). The changes of $\Delta \Psi_{\mathrm{m}}$ were determined measuring the fluorescence of cells labeled with CMXRos (B). The DEVDase activity was determined by fluorometry (C). Data show the mean \pm S.D. of four experiments. ${ }^{*} P<0.05$, ${ }^{* *} P<0.01$ with respect to the control condition

change of $\Delta \Psi_{\mathrm{m}}$ is sufficient for the leakage of mitochondrial molecules, among them cytochrome $c$.

\section{NO-dependent apoptosis in macrophages may occur in the absence of apoptotic volume decrease (AVD)}

The relevance of AVD on the apoptosis induced by NOdonors and staurosporine was investigated in RAW 264.7 and HeLa cells. As Figure 4A,B shows, incubation of RAW 264.7 cells with phloretin and SITS, two inhibitors of volumesensitive $\mathrm{Cl}^{-}$channels, ${ }^{7}$ abrogated the apoptosis induced by staurosporine, but not that triggered by NO. Indeed, both phloretin and SITS suppressed AVD in these cells. Under conditions of AVD inhibition, the increase in $\Delta \Psi_{\mathrm{m}}$ induced by GSNO and staurosporine and characteristic of RAW 264.7 cells, was significantly inhibited (Figure 4C). However, the release of cytochrome $c$ to the cytosol and the activation of DEVDase were unaffected by phloretin and SITS in cells treated with GSNO, but were markedly impaired in cells incubated with staurosporine (Figure 4D,E). In view of the specific effects of $\mathrm{NO}$ in macrophage apoptosis the time course of the values of $\Delta \Psi_{\mathrm{m}}$, the in vivo activation of caspase 3 (using cells loaded with PhyPhyLuxG1D2) and the average cell volume were determined. As Figure $5 \mathrm{~A}-\mathrm{C}$ shows, the increase in CMXRos fluorescence was very rapid and preceded AVD and caspase 3 activation. Interestingly, SITS inhibited AVD, and to a lesser extent $\Delta \Psi_{\mathrm{m}}$, but failed to prevent the release of cytochrome $c$ (Figure $4 \mathrm{~B}$ ) and in vivo activation of caspase 3 (Figure 5). A microphotograph of cells corresponding to each incubation condition at $1 \mathrm{~h}$ is shown in Figure 5D.

When experiments similar to those performed with RAW 264.7 macrophages were repeated in HeLa cells, AVD inhibitors prevented efficiently the apoptosis induced by GSNO and staurosporine and blocked the changes of CMXRos fluorescence, cytochrome $c$ release and DEVDase activation (Figure 6A-D). These results stress the relevance of cell-specific regulation of apoptotic pathways and, at the same time, suggest the existence of a cross regulation between the different steps involved in the apoptotic response. A summary of the contribution of early events to apoptosis in the distinct cell types analyzed is shown in Table 1.

\section{Discussion}

The relevance of the loss of $\Delta \Psi_{\mathrm{m}}$ as an early event preceding the release of mitochondrial mediators of apoptosis has been established in various cell types. ${ }^{1-3}$ However, in HeLa cells treated with UV radiation, $\Delta \Psi_{\mathrm{m}}$ changes followed the release of cytochrome $c$ to the cytosol, an event that was not prevented by permeability transition inhibitors. ${ }^{22}$ Moreover, an increase in $\Delta \Psi_{m}$ has been described in macrophages undergoing NO-dependent apoptosis. ${ }^{20}$ Here we show that incubation of macrophages with GSNO, camptothecin, etoposide and, to a lesser extent staurosporine, increased $\Delta \Psi_{\mathrm{m}}$. However, $\mathrm{NO}$ and the other apoptogenic stimuli decreased $\Delta \Psi_{\mathrm{m}}$ in HeLa and Jurkat T cells $^{20,23}$ (and this study). The changes of $\Delta \Psi_{m}$ have been measured following the fluorescence of CMXRos but similar 


\section{HeLa}
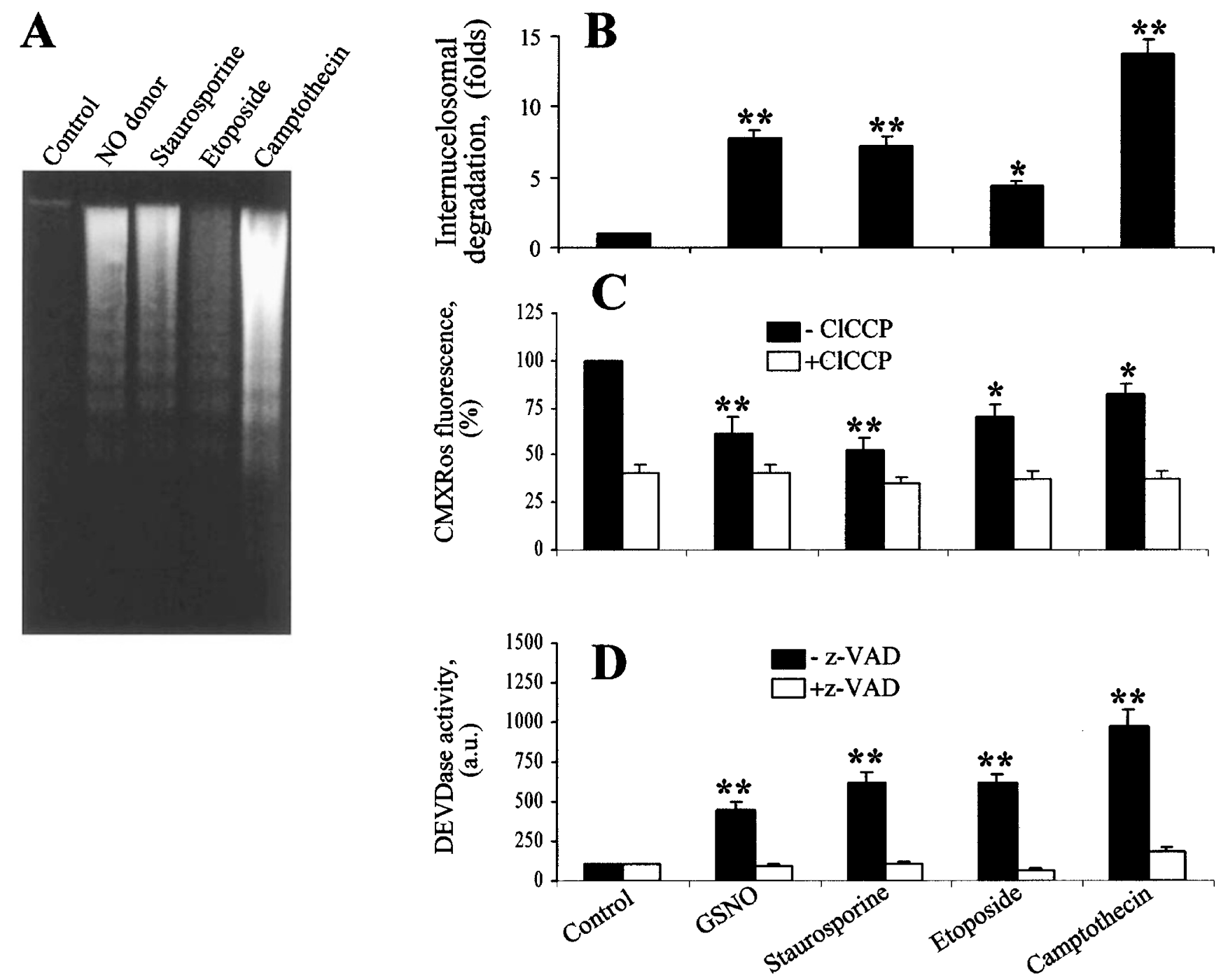

Figure 3 Characterization of apoptosis in HeLa cells. Apoptosis was induced as described in Figure 1 and the fragmentation of the DNA was determined in agarose gels (A), and quantified by measuring the presence of oligonucleosomes in the cytosol (B). The changes of $\Delta \Psi_{\mathrm{m}}$ were determined by measuring the CMXRos fluorescence (C). The DEVDase activity was determined by fluorometry (D). Data show the mean \pm S.D. of four experiments. ${ }^{\star} P<0.05,{ }^{*} P<0.01$ with respect to the control condition

results were obtained with other probes such as JC1 (tetrachlorotetraethylbenzimidazolylcarbocyanine iodide) and Dioc $_{6(3)}$ (3,3'-dihexyloxacarbocyanine iodide; not shown). These data indicate that the cell type is an important factor determining the irreversible (increase or decrease) change of $\Delta \Psi_{\mathrm{m}}$ during apoptotic stimulation. However, regardless of the sign of the $\Delta \Psi_{\mathrm{m}}$ changes, a release of cytochrome $c$ from the mitochondria to the cytosol was observed in all cases and this was sufficient for the activation of the caspase cascade.

The other objective investigated in this study was the relevance of AVD on apoptosis, in particular in response to
NO challenge. NO released at low doses, such as those achieved after activation of the NOS-3 isoenzyme by $\mathrm{Ca}^{2+}$ / calmodulin, has been usually associated with the activation of $\mathrm{K}^{+}$channels in vascular smooth muscle and endothelial cells, and accounted for the vasodilation capacity of NO. ${ }^{24,25}$ Moreover, the existence of a $\mathrm{K}^{+} / \mathrm{Cl}^{-}$cotransport regulated by $\mathrm{NO}$ has been proposed. ${ }^{26}$ However, it is possible that at higher doses $\mathrm{NO}$ modifies the activity of $\mathrm{K}^{+}$ channels through other mechanisms, including nitrosylation reactions. ${ }^{27}$ Indeed, a selective specificity has been described for different $\mathrm{K}^{+}$channels ${ }^{28}$ and, for example, inhibition of the $\mathrm{K}^{+}$outward efflux depending on the ether-a- 


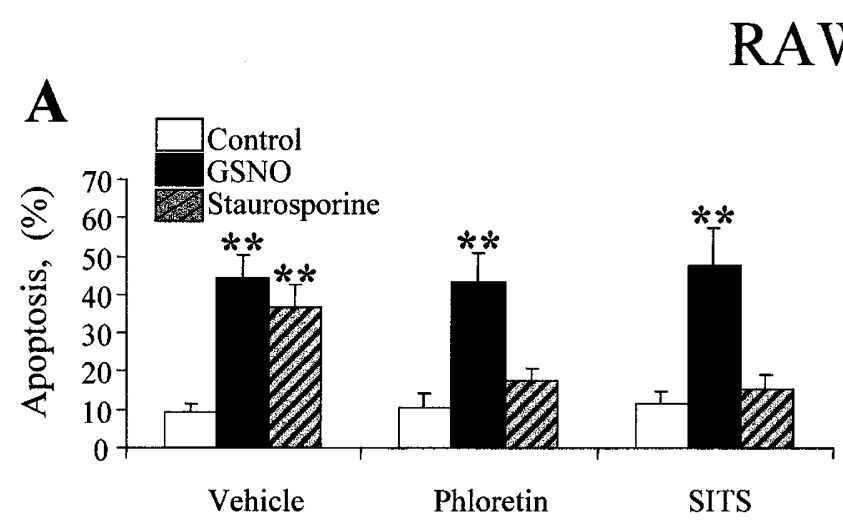

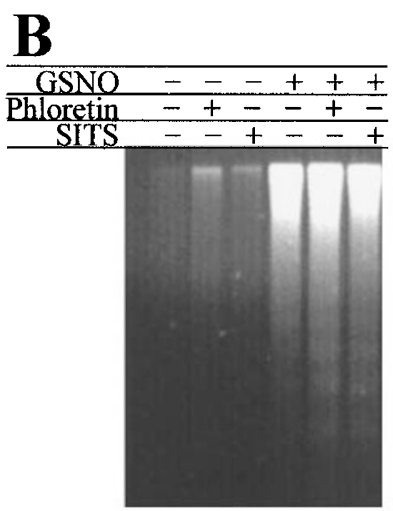

Cyt c

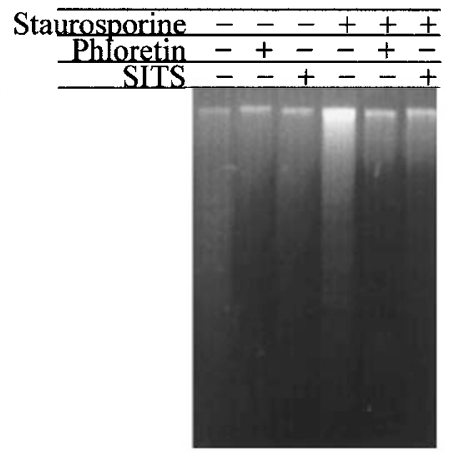

Cyt c
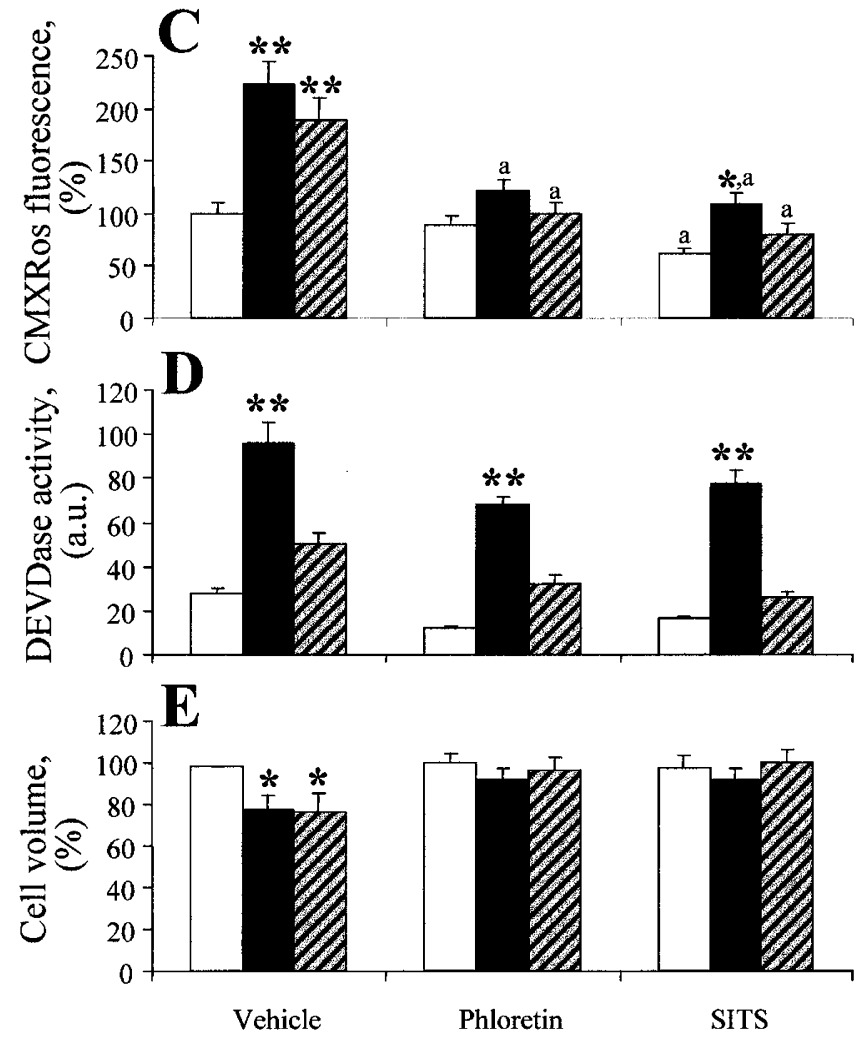

Figure 4 Inhibition of AVD and apoptosis in RAW 264.7 cells. Macrophages were incubated with the volume-sensitive $\mathrm{Cl}^{-}$channel inhibitors phloretin (30 $\mu$ M) and SITS $(0.5 \mathrm{mM})$ and apoptosis was induced as described in Figure 1. The percentage of apoptotic cells was determined by flow cytometry (A) and the fragmentation of the DNA was analyzed in agarose gels (B). The changes of $\Delta \Psi_{\mathrm{m}}$ were determined by flow cytometry in cells labeled with CMXRos (C). The DEVDase activity was measured by fluorometry (D), and the cell size was determined by flow cytometry (E). The release of cytochrome $c$ to the cytosol was

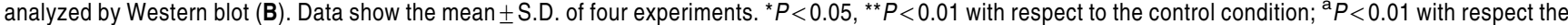
corresponding vehicle condition

gogo-related gene-1 (hERG1) was found to be inhibited by high concentrations of $\mathrm{NO}$ donors. ${ }^{29}$ In the context of apoptosis dependent on the activation of $\mathrm{K}^{+}$channels, an enhanced survival of vascular smooth muscle cells that overexpress $\mathrm{Bcl}-2$ has been associated to a lower activity of the $\mathrm{K}^{+}$channel. ${ }^{30}$ Also, inhibitors of $\mathrm{K}^{+}$channels attenuate apoptosis in various cell types. ${ }^{17,31-33}$ These data suggest that cells can support physiological activation of the $\mathrm{K}^{+}$channels without effects on cell viability, and only when the intracellular $\mathrm{K}^{+}$concentration is below a critical level, established by several groups around $50-100 \mathrm{mM}$, that cells display the characteristic AVD. ${ }^{5,14,31}$ In the systematic study carried out by Maeno et al., ${ }^{7}$ inhibition of AVD suppressed apoptosis in different cell types treated with stimuli that involved the release of mitochondrial mediators as well as the activation of apoptotic pathways through plasma membrane receptors (TNF- $\alpha$ plus cycloheximide). We confirmed that inhibition of AVD prevented apoptosis in most circumstances, except in macrophages treated with apoptogenic doses of NO. However, this AVDindependent apoptosis induced by NO appears to be cell specific since it was observed in macrophages, but not in
HeLa and Jurkat T cells. Moreover, staurosporine-induced apoptosis in macrophages was efficiently prevented by all AVD inhibitors assayed suggesting that the effect of NO in these cells is very specific and probably related to the functional role of NO in macrophage physiology.

The time course of AVD has been also a subject of debate. Some groups detected AVD early the apoptotic signaling, ${ }^{7}$ whereas other described AVD after caspase activation. ${ }^{14}$ Indeed, caspase inhibitors can prevent AVD, for example in thymocytes treated with dexamethasone ${ }^{13}$ and in $\mathrm{B}$ lymphocytes incubated with $\operatorname{TGF} \beta .^{34}$ In this regard, it is possible that activation of some caspases would be sufficient for the initiation of AVD, ${ }^{34,35}$ and this might explain the effectiveness of broad caspase inhibitors preventing AVD and apoptosis. We analyzed the changes of $\Delta \Psi_{\mathrm{m}}$, cell volume and activation of caspase 3 to establish the temporal sequence of these events in macrophages and concluded from these experiments that the increase in $\Delta \Psi_{\mathrm{m}}$ occurred in the absence of measurable AVD. Moreover, caspase 3 activation and AVD started 30 min after treatment with apoptotic stimuli and exhibited a parallel profile. It is worth mentioning that inhibitors of AVD 


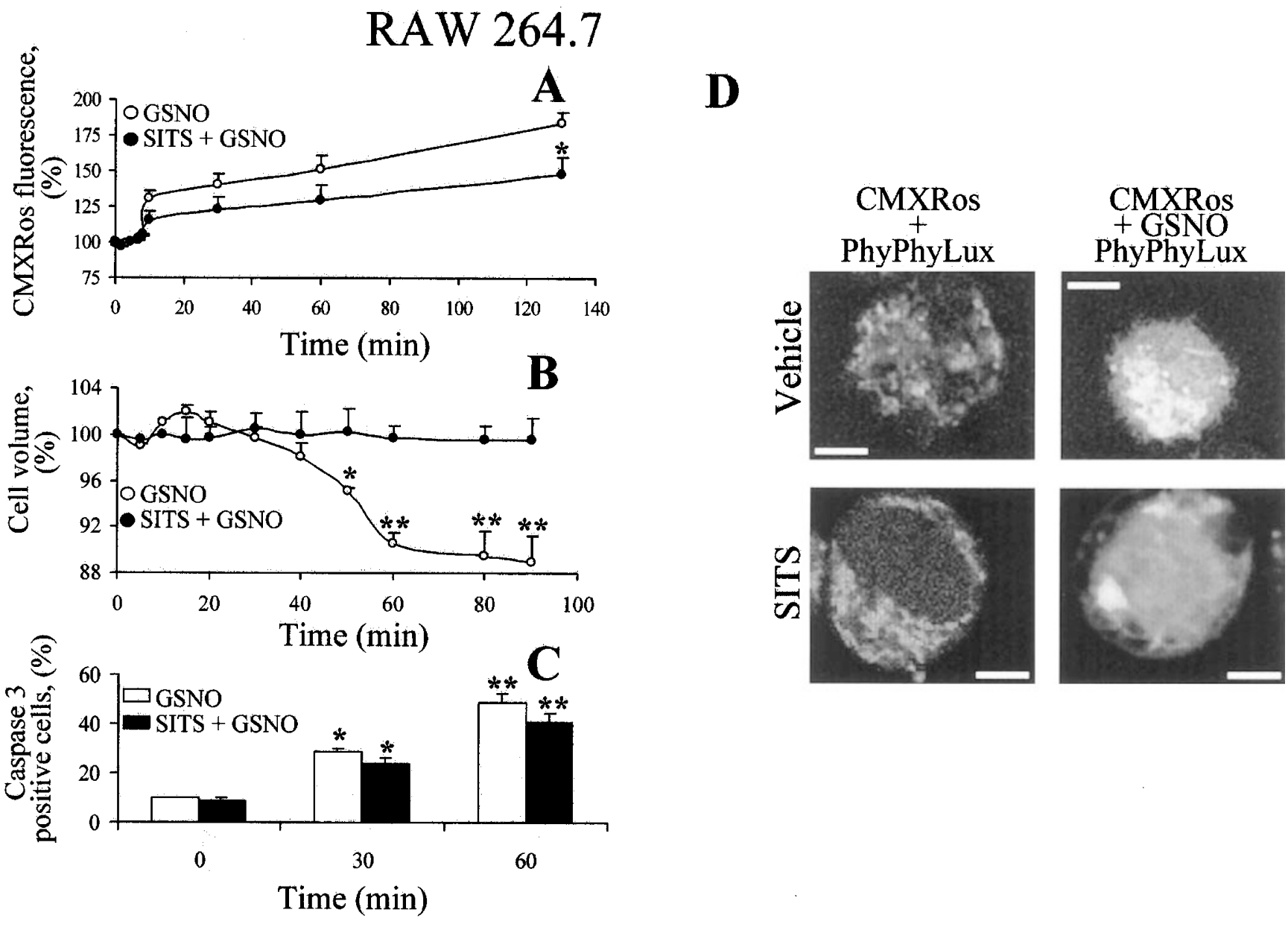

Figure 5 Time-course of $\Delta \Psi_{m}, A V D$ and caspase activation in macrophages treated with GSNO. Cells were incubated with $0.5 \mathrm{mM}$ SITS and then challenged with $1 \mathrm{mM}$ GSNO. The time course of $\Delta \Psi_{\mathrm{m}}(\mathbf{A})$, the average cell volume $(\mathbf{B})$ and the percentage of caspase 3-active cells, determined by the fluorescence of PhyPhyLux were plotted (C). A confocal microphotograph representative of cells from each condition is shown; bar $=5 \mu \mathrm{m}(\mathbf{D})$. The particulate grey fluorescence corresponds to CMXRos labeling of mitochondria, and the diffuse fluorescence to the cleavage of the PhyPhyLux peptide. Bright areas show the overlapping of CMXRos and PhyPhyLux fluorescences (right panels). Data show the mean \pm S.D. of four experiments. ${ }^{*} P<0.05,{ }^{* \star} P<0.01$ with respect to the control condition

reduced the amplitude of $\Delta \Psi_{\mathrm{m}}$ changes even in the absence of alterations in cell volume, at least in macrophages challenged with GSNO and staurosporine.

Taken together, these results indicate that different pathways convey to regulate the initial steps of apoptosis leading to the release of cytochrome $c$ and other mitochondrial effectors, such as apoptosis inducing factor (AIF). The existence of cell type specificity in the response to a particular pro-apoptotic stimulus opens the possibility of new strategies in the regulation of apoptosis under pathological circumstances.

\section{Materials and Methods}

\section{Chemicals}

Reagents were from Roche (Mannheim, Germany), Calbiochem (Darmstadt, Germany) and Sigma (St. Louis, MO, USA). Fluorescent probes were from Molecular Probes (Eugene, OR, USA). Antibodies were from (Becton \& Dickinson, San Jose, CA, USA). Culture media were from Biowhittaker (Verviers, Belgium).

\section{Cell culture conditions}

The murine macrophage cell line RAW 264.7, the human Jurkat T cell line and HeLa cells were maintained in RPMI 1640 medium supplemented with 10\% FCS, L-glutamine and antibiotics.

\section{Flow cytometric analysis of apoptosis and cell size}

PI staining was performed following a previous protocol. ${ }^{20,36,37}$ Cells were resuspended in PBS and analyzed in a FACScan cytometer (Becton \& Dickinson) equipped with a 25-mW argon laser. The quantification of the percentage of apoptotic cells was assessed using a dot plot of the forward scatter against the PI fluorescence. Cell sorting and analysis of DNA integrity of viable and apoptotic populations was performed to confirm the criteria of gating. In HeLa cells, apoptosis was determined by measuring the oligonucleosomal 


\section{HeLa}
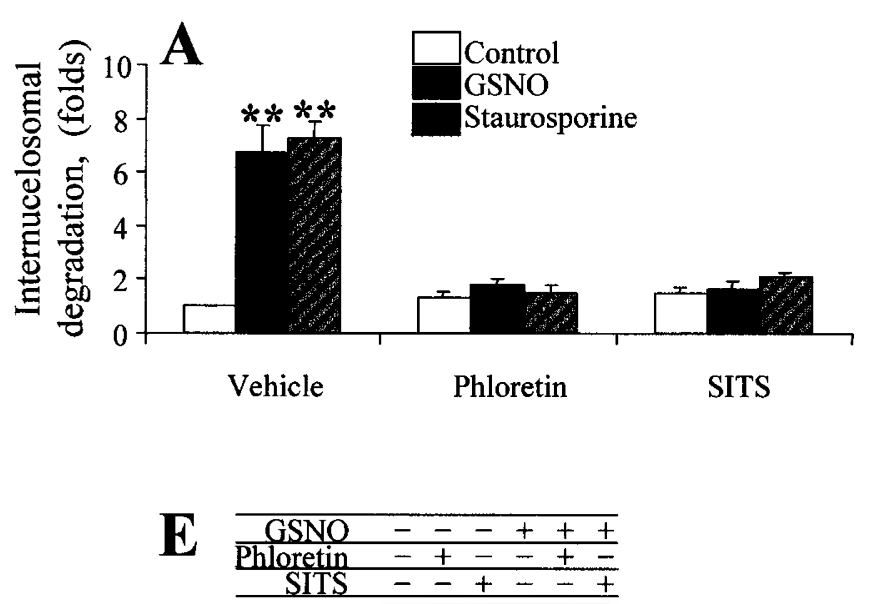

Cyt c

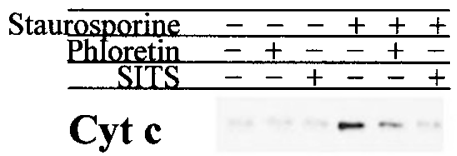

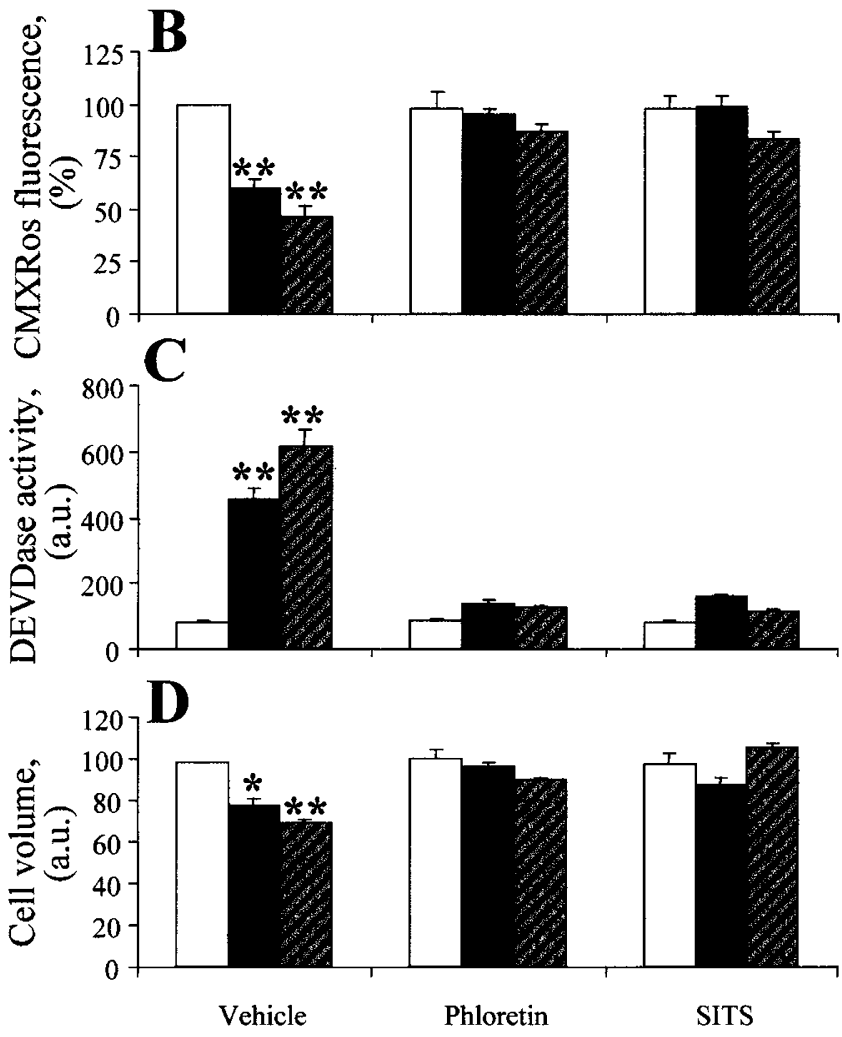

Figure 6 Inhibition of AVD and apoptosis in HeLa cells. Cells were incubated with $30 \mathrm{mM}$ phloretin, $0.5 \mu \mathrm{M}$ SITS or vehicle and apoptosis was induced with $1 \mathrm{mM}$ GSNO or $200 \mathrm{nM}$ staurosporine. The percentage of apoptotic cells was determined measuring the release of oligonucleosomes to the cytosol (A). The changes of $\Delta \Psi_{m}$ were determined by measuring the CMXRos fluorescence (B). The DEVDase activity was determined by fluorometry (C), and the cell volume was analyzed by flow cytometry (D). The release of cytochrome $c$ to the cytosol was determined by Western blot (E). Data show the mean $\pm S$.D. of four experiments. ${ }^{*} P<0.05$, ${ }^{* *} P<0.01$ with respect to the control condition

DNA present in the cytosol using an ELISA cell death kit (Roche) in which the histone associated DNA fragments were detected in a sandwich-enzyme-immunoassay with anti-histone and anti-DNAperoxidase antibodies, following the instructions of the supplier. Cell volume was determined by flow cytometry based on the size of latex beads of known volume. The cell size was also electronically evaluated by confocal microscopy in an MRC 1024 microscope (BioRad) using Lasersharp software.

\section{Flow cytometric analysis of $\Delta \Psi_{\mathrm{m}}$}

Cells were incubated for $15 \mathrm{~min}$ at $37^{\circ} \mathrm{C}$ in the presence of the potential-sensitive probe $\mathrm{CMXRos}^{23}$ followed by analysis in a FACSscan flow cytometer. The fluorescence in the presence of $10 \mu \mathrm{M}$ of the uncoupling agent $m \mathrm{CICCP}$ was measured to define the maximal decrease of $\Delta \Psi_{\mathrm{m}}$. The fluorescence of CMXRos in untreated cells was considered as $100 \%$.

\section{Release of cytochrome $c$ from the mitochondria to the cytosol}

The presence of cytochrome $c$ in the cytosol was determined by Western blotting cell extracts obtained by controlled lysis of the plasma membrane as previously described. ${ }^{20}$ The proteins were sizeseparated in $12 \%$ SDS-PAGE, transferred to a PVDF membrane and incubated with anti-cytochrome $c$ Ab (Santa Cruz). The bands recognized were visualized by the ECL technique.

\section{In vitro and in vivo caspase assays}

For in vitro assays, cell extracts were prepared in $10 \mathrm{mM}$ HEPES, pH 7.9; 1 mM EDTA, 1 mM EGTA, $120 \mathrm{mM} \mathrm{NaCl}, 1 \mathrm{mM}$ DTT, $0.5 \mathrm{mM}$ PMSF, $2 \mu \mathrm{g} / \mathrm{ml}$ aprotinin, $10 \mu \mathrm{g} / \mathrm{ml}$ leupeptin, $2 \mu \mathrm{g} / \mathrm{ml}$ TLCK, $5 \mathrm{mM}$ $\mathrm{NaF}, 1 \mathrm{mM} \mathrm{NaVO}{ }_{4}, 10 \mathrm{mM} \mathrm{Na}_{2} \mathrm{MoO}_{4}$ and $0.5 \%$ Nonidet P-40. After centrifugation of the cell lysate the supernatant was stored at $-80^{\circ} \mathrm{C}$ (cytosolic extract) and protein content was assayed using the Bio-Rad protein reagent. The DEVDase (corresponding mainly to caspases 3 and 7) and caspase 9 activities were determined in cell lysates using $\mathrm{N}$-acetyl-DEVD-AFC and N-acetyl-LEHD-AFC as fluorogenic substrates and following the instructions of the supplier (Calbiochem). The linearity of the caspase assay was determined over a $30 \mathrm{~min}$ reaction period. In vivo activation of caspase 3 was measured after labeling the cells with PhiPhiLux-G1D2 (a derivative of GDEVDGI that yields a fluorescent peptide after caspase cleavage, Oncolmmunin, Gaithersburg, MD, USA), and following the instructions of the supplier. ${ }^{38}$ 


\section{Statistical analysis}

The data shown are the mean \pm S.D. $(n=3-4)$. Statistical significance was determined with the Student's $t$-test for unpaired observations. A $P<0.05$ was considered significant. In studies of Western blot analysis, linear correlation between increasing amounts of input protein and signal intensity were observed (correlation coefficients $>0.8)$.

\section{Acknowledgements}

The authors thank Dr MA Moro and Dr I Rodríguez Crespo for critical reading of the manuscript and to $G$ Stanford for help in the preparation of the text. This work was supported by grants PM98-0120 from Comisión Interministerial de Ciencia y Tecnología (Spain), and 08.3/0010/00 from Comunidad de Madrid (Spain).

\section{References}

1. Kroemer G, Dallaporta B and Resche-Rigon M (1998) The mitochondrial death/ life regulator in apoptosis and necrosis. Annu. Rev. Physiol. 60: 619-642

2. Green DR and Reed JC (1998) Mitochondria and apoptosis. Science 281:13091312

3. Kroemer G and Reed JC (2000) Mitochondrial control of cell death. Nat. Med. 6: $513-519$

4. Kerr JF, Wyllie AH and Currie AR (1972) Apoptosis: a basic biological phenomenon with wide-ranging implications in tissue kinetics. Br. J. Cancer 26: 239-257

5. Bortner CD and Cidlowski JA (1998) A necessary role for cell shrinkage in apoptosis. Biochem. Pharmacol. 56: 1549-1559

6. Gomez-Angelats M, Bortner CD and Cidlowski JA (2000) Cell volume regulation in immune cell apoptosis. Cell Tissue Res. 301: 33-42

7. Maeno E, Ishizaki Y, Kanaseki T, Hazama A, Okada Y (2000) Normotonic cell shrinkage because of disordered volume regulation is an early prerequisite to apoptosis. Proc. Natl. Acad. Sci. USA 97: 9487-9492

8. Okada Y, Maeno E, Shimizu T, Dezaki K, Wang J and Morishima S (2001) Receptor-mediated control of regulatory volume decrease (RVD) and apoptotic volume decrease (AVD). J. Physiol. 532: 3-16

9. Chang SH, Phelps PC, Berezesky IK, Ebersberger MLJ and Trump BF (2000) Studies on the mechanisms and kinetics of apoptosis induced by microinjection of cytochrome c in rat kidney tubule epithelial cells (NRK-52E). Am. JPathol. 156 637-649

10. Deshmukh M, Johnson EMJ (1997) Programmed cell death in neurons: focus on the pathway of nerve growth factor deprivation-induced death of sympathetic neurons. Mol. Pharmacol. 51: 897-906

11. Lepple-Wienhues A, Szabo I, Laun T, Kaba NK, Gulbins E and Lang F (1998) The tyrosine kinase p56lck mediates activation of swelling-induced chloride channels in lymphocytes. J. Cell. Biol. 141: 281-286

12. Zamzami N, Marchetti P, Castedo M, Decaudin D, Macho A, Hirsch T, Susin SA, PetitPX, Mignotte B and Kroemer G (1995) Sequential reduction of mitochondrial transmembrane potential and generation of reactive oxygen species in early programmed cell death. J. Exp. Med. 182: 367-377

13. Hughes FMJ and Cidlowski JA (1998) Glucocorticoid-induced thymocyte apoptosis: protease-dependent activation of cell shrinkage and DNA degradation. J. Steroid Biochem. Mol. Biol. 65: 207-217

14. Yu SP and Choi DW (2000) lons, cell volume, and apoptosis. Proc. Natl. Acad. Sci. USA 97: 9360-9362

15. Dallaporta B, Hirsch T, Susin SA, Zamzami N, Larochette N, Brenner C, Marzo I and Kroemer $\mathrm{G}$ (1998) Potassium leakage during the apoptotic degradation phase. J. Immunol. 160: 5605-5615

16. Allbritton NL, Verret CR, Wolley RC and Eisen HN (1988) Calcium ion concentrations and DNA fragmentation in target cell destruction by murine cloned cytotoxic T lymphocytes. J. Exp. Med. 167: 514-527
17. Beauvais F, Michel $L$ and Dubertret $L$ (1995) Human eosinophils in culture undergo a striking and rapid shrinkage during apoptosis. Role of $\mathrm{K}+$ channels. J. Leukoc. Biol. 57: 851-855

18. Kroemer G, Zamzami N and Susin SA (1997) Mitochondrial control of apoptosis. Immunol Today 18: 44-51

19. Green DR (1998) Apoptotic pathways: the roads to ruin. Cell 94: $695-698$

20. Hortelano S, Alvarez AM and Bosca L (1999) Nitric oxide induces tyrosine nitration and release of cytochrome $c$ preceding an increase of mitochondrial transmembrane potential in macrophages. FASEB J. 13: 2311-2317

21. Hortelano S, Castrillo A, Alvarez AM and Bosca L (2000) Contribution of cyclopentenone prostaglandins to the resolution of inflammation through the potentiation of apoptosis in activated macrophages. J. Immunol. 165: 65256531

22. Bossy-Wetzel E, NewmeyerDD and Green DR (1998) Mitochondrial cytochrome c release in apoptosis occurs upstream of DEVD-specific caspase activation and independently of mitochondrial transmembrane depolarization. EMBO J. 17: $37-49$

23. Hortelano S, Dallaporta B, Zamzami N, Hirsch T, Susin SA, Marzo I, Bosca L and Kroemer $\mathrm{G}$ (1997) Nitric oxide induces apoptosis via triggering mitochondrial permeability transition. FEBS Lett 410: 373-377

24. Shieh CC, Coghlan M, Sullivan JP and Gopalakrishnan M (2000) Potassium channels: molecular defects, diseases, and therapeutic opportunities. Pharmacol. Rev. 52: 557-594

25. Sobey CG (2001) Potassium channel function in vascular disease. Arterioscler. Thromb.Vasc. Biol. 21: 28-38

26. Adragna NC, White RE, Orlov SN and Lauf PK (2000) K-Cl cotransport in vascular smooth muscle and erythrocytes: possible implication in vasodilation. Am. J. Physiol. Cell Physiol. 278: C381-C390

27. Stamler JS (1995) S-nitrosothiols and the bioregulatory actions of nitrogen oxides through reactions with thiol groups. Curr. Top Microbiol Immunol. 196: $19-36$

28. Martens JR, Navarro-Polanco R, Coppock EA, Nishiyama A, Parshley L, Grobaski TD and Tamkun MM (2000) Differential targeting of Shaker-like potassium channels to lipid rafts. J. Biol. Chem. 275: 7443-7446

29. Taglialatela M, Pannaccione A, lossa S, Castaldo P and Annunziato L (1999) Modulation of the $\mathrm{K}(+)$ channels encoded by the human ether-a-gogo-related gene-1 (hERG1) by nitric oxide. Mol. Pharmacol. 56: 1298-1308

30. Ekhterae D, Platoshyn O, Krick S, Yu Y, McDaniel SS and Yuan JX (2001) Bcl-2 decreases voltage-gated $\mathrm{K}(+)$ channel activity and enhances survival in vascular smooth muscle cells. Am. J. Physiol. Cell Physiol. 281: C157-C165

31. Montague JW, Bortner CD, Hughes FMJ and Cidlowski JA (1999) A necessary role for reduced intracellular potassium during the DNA degradation phase of apoptosis. Steroids 64: 563-569

32. Bortner CD, Gomez-Angelats M and Cidlowski JA (2001) Plasma membrane depolarization without repolarization is an early molecular event in anti-Fasinduced apoptosis. J. Biol. Chem. 276: 4304-4314

33. Bortner CD and Cidlowski JA (1999) Caspase independent/dependent regulation of $\mathrm{K}(+)$, cell shrinkage, and mitochondrial membrane potential during lymphocyte apoptosis. J. Biol. Chem. 274: 21953-21962

34. Schrantz N, Blanchard DA, Auffredou MT, Sharma S, Leca G and Vazquez A (1999) Role of caspases and possible involvement of retinoblastoma protein during TGF $\beta$-mediated apoptosis of human B lymphocytes. Oncogene 18: $3511-3519$

35. Zhivotovsky B, Gahm A, Ankarcrona M, Nicotera P and Orrenius S (1995) Multiple proteases are involved in thymocyte apoptosis. Exp. Cell Res. 221: 404-412

36. Hortelano S, López-Collazo A and Boscá L (1999) Protective effect of cyclosporin A and FK506 from nitric oxide-dependent apoptosis in activated macrophages. Brit. J. Pharmacol, 126: 1139-1146

37. Genaro AM, Hortelano S, Alvarez A, Martinez C and Bosca L (1995) Splenic B lymphocyte programmed cell death is prevented by nitric oxide release through mechanisms involving sustained Bcl-2 levels. J. Clin. Invest. 95: 1884-1890

38. Komoriya A, Packard BZ, Brown MJ, Wu ML and Henkart PA (2000) Assessment of caspase activities in intact apoptotic thymocytes using cell-permeable fluorogenic caspase substrates. J. Exp. Med. 191: 1819-1828 